\title{
Nutritional Status and Associated Factors among Pregnant Women in Wondo Genet District, Southern Ethiopia
}

\author{
Desalegn Kuche ${ }^{1}$, Pragya Singh ${ }^{2}$, Debebe Moges ${ }^{2}$ and Tefera Belachew ${ }^{3}$ \\ 1. Food Science and Nutrition Research Directorate, Ethiopian Public Health Institute, P.O. Box 1242/5654, Gulelle Arbegnoch \\ Street (Former Pasteur Institute), Gulele Sub City, Addis Ababa, Ethiopia \\ 2. School of Nutrition, Food Science and Technology, Department of Applied Human Nutrition, Awassa College of Agriculture, \\ Hawassa University, P.O. Box 05, Hawassa, Ethiopia \\ 3. Department of Population and Family Health, College of Medicine and Health Science, Jima University, P.O. Box 378, Jima, \\ Ethiopia
}

\begin{abstract}
Inadequate quality and quantity diet is one of the major reasons for high levels of malnutrition in pregnant women. A cross-sectional survey was conducted in Wondo Genet District, Southern Ethiopia. A two-stage cluster sampling technique was used to select a representative sample of 153 pregnant women aged 19-49 years from three rural villages ("Kebeles"). Energy and nutrient intakes from foods were calculated from one-day weighed food records on a sub-sample $(n=77)$. The result of the study showed that the intakes of most nutrients were lower than the recommended intake. The energy intake of the study participants both in $2 \mathrm{nd}$ and $3 \mathrm{rd}$ trimesters of pregnancy were 2,308 kcal and 1,420.5 kcal compared to the recommended 2,340 kcal and 2,452 kcal, respectively. Except iron, almost all micronutrient intakes were lower than the recommended intake. Vitamin A intake was $3 \mu \mathrm{g}$ compared with the recommended $800 \mu \mathrm{g}$, while protein intake of the study respondents in $2 \mathrm{nd}$ and $3 \mathrm{rd}$ trimester of pregnancy was $45.9 \mathrm{~g}$ and $31.5 \mathrm{~g}$, respectively, compared with the recommended $71 \mathrm{~g}$. Risk factors for undernutrition were multiple pregnancy and no consumption of cereal-based foods. This study revealed that the energy and nutrient intake of the pregnant women in study area was below the recommended intakes. Furthermore, the situation might be aggravated by high phytate content food consumption reported. Nutritional status of pregnant women in study area was not adequate to support the increased energy and nutrient requirement of the participants.
\end{abstract}

Key words: Pregnant women, nutritional status, vitamins, energy, protein, Southern Ethiopia.

\section{Introduction}

Adequate nutritional status of pregnant mothers is essential for their health and pregnancy outcomes. Due to increased nutritional requirements, pregnancy is a critical period for meeting the body's demand for macro and micronutrients. Thus, anemia and vitamin A deficiency (VAD) are common micronutrient deficiencies, which affecting 53.8 million pregnant women in the world $[1,2]$. The deficiency has been

Corresponding author: Desalegn Kuche, M.Sc., research fields: nutrition, food science and health. E-mail: desukuche@gmail.com. shown to result in serious health consequences, including increased morbidity and mortality of both mother and child [3]. Malnutrition is globally the most important risk factor for illness and death with hundreds of millions of pregnant women [4, 5].

Poor nutrition in pregnancy in combination with infections is a common cause of maternal and infant mortality and morbidity, low birth weight and intrauterine growth retardation (IUGR) [6]. Malnutrition remains one of the world's highest priority health issues, not only because its effects are so widespread and long lasting but also it can be eradicated best at the preventive stage [7]. 
Direct consequences of chronic energy deficiency among women include increasing susceptibility to infection, reducing activity levels and lowering productivity [8]. It was documented that changes in food-related behaviors take place more often during pregnancy than at any other stage of life [9]. Pregnant women need to increase food intake to fulfill the increased energy need associated with the growth of the fetus. Women decreasing their energy intake have a higher risk of preterm delivery [10].

The correlation between the caloric intake and maternal weight gain during pregnancy and the birth weight of infant is well established. Low birth weight is closely associated with growth retardation, poor cognitive performance, morbidity and mortality during childhood, and it leads to increased susceptibility to chronic diseases, such as cardiovascular disease, diabetes mellitus and hypertension at later age [11].

In the developing world as a whole, one in five newborns is low birth weight. South Asia contributes the highest number of low birth weight infant with one in two being born with low birth weight [12]. According to the study by the Ethiopian Ministry of Economic Development and Cooperation, 50\% of the Ethiopian population are living below the food poverty line and cannot meet their daily minimum nutritional requirement of 2,200 calories [13]. A woman who has poor nutritional status as indicated by a low body mass index (BMI), short stature, anaemia or other micronutrient deficiency, has a greater risk of obstructed labor-having a baby with a low birth weight, producing lower quality breast milk, death due to postpartum hemorrhage and illness for herself and her baby [14].

The needs for most nutrients are increased during pregnancy to meet the high demands for the growth of both fetus and the mother. It increases energy need by about $13 \%$, protein need by $54 \%$ and vitamin and mineral need by $0 \%-50 \%$, depending on the vitamin or mineral required $[15,16]$. Therefore, during pregnancy, it is very difficult to achieve the recommended intakes of certain nutrients (such as iron) without the use of fortified products or vitamin-mineral supplements. On the other hand, most nutritionists believe that focusing on food choices is the best long-term approach for improving nutrition [17]. Many African women consume less than the recommended daily caloric intake and 5\%-20\% are underweight. Pregnant women in industrialized countries gain on average twice as much as pregnant women in Africa. In 12/17 African countries, $10 \%$ or more of babies are born with low birth weight. Inadequate micronutrient intake, particularly of iron, vitamin A, zinc, folic acid, riboflavin, iodine and vitamin $\mathrm{E}$, is also common in Africa.

Other factors affecting women's nutritional status are energy expenditures and the demands of pregnancy and lactation [18]. A comparative study on maternal nutritional status in 16 of the 18 DHS conducted countries and a study in the Southern Nations Nationalities Peoples Region of Ethiopia (SNNPR) showed that rural women are more likely to suffer from chronic energy deficiency than women in urban areas $[19,20]$. These higher rates of rural malnutrition were also reported by local studies in Ethiopia [21, 22]. Despite the efforts of the federal ministry of health and its stakeholders, 2011 demographic health survey (DHS) of Ethiopia showed that $27 \%$ of women aged $15-49$ years were chronically malnourished and about 17\% suffered from anemia with significant regional variations [23]. To address this problem, the government of Ethiopia developed a national nutrition program in 2008, which targeted pregnant and lactating women and interventions had been going on through the routine health care services. There is no study that documented the nutritional status and associated factors among pregnant women after the introduction of the national nutrition program.

The objective of this study was to assess the nutritional status and associated factors among 
pregnant women in Wondo Genet District, Southern Ethiopia.

\section{Materials and Methods}

\subsection{Study Setting and Sample}

The study was carried out in Wondo Genet District located Southeast of Shashemene in Sidama Zone, SNNPR, Ethiopia. There are 13 rural and one urban kebeles in the district, but this study was carried out in rural areas of the district. Total population of Wondo Genet District was estimated to be 137,010 , of which 114,716 were rural and 22,294 were urban population. The number of women of reproductive age in rural areas was 26,729. Out of these women in the reproductive age, 5,010 women were estimated to be pregnant.

\subsection{Study Design and Materials}

A cross-sectional community based survey was carried. The source population for this study was pregnant women aged 19-49 years residing in rural community of the district. The study population was all pregnant women in the 2nd and 3rd trimester of pregnancy, who were identified and included in the study with the help of health professionals and having information from their antenatal care document in health center. Based on an assessment of fundal height performed by nurses, the pregnant women were classified into 2 nd and 3rd trimester of pregnancy and their dietary intakes were assessed. A structured and pre-tested questionnaire was used to gather data related to the objectives of the study. Height measuring board and mid-upper arm circumference (MUAC) measuring tape were used to collect anthropometric data of pregnant women in the study. During anthropometric measurement, height and MUAC were measured in duplicate on each pregnant woman.

\subsection{Sample Size}

The sample size was calculated based on the previous research which showed the prevalence of inadequate dietary iron intake among pregnant women in Sidama population was 4\% [24]. Based on statistical formula, the total sample size calculated for this study was 153. Design effect and default were considered in the sample size calculation. Two-stage cluster sampling technique was used to select a representative sample. On the first stage, the list of existing kebeles of the district was obtained from the Wondo Genet district health office. Then, out of the total 13 kebeles, three kebeles were selected using probability proportional to size. Selection of individuals in the selected clusters was done in the second stage. In this stage, the sample size was assigned to each of the three kebeles selected. Individual women were randomly selected and stratified according to their gestational age for dietary intake assessment and interviewed at their respective homes.

\subsection{Dietary Assessment}

For dietary intake assessment, one-day weighed food record was taken by well trained data collectors. Weekdays and weekend days were proportionately represented in the survey to account for any day-of-the-week effects on food intake. Foods and beverages consumed by pregnant women were weighed as described by Gibson and Ferguson [25]. The energy and nutrient content of the foods consumed were calculated using Ethiopian food composition table [26]. Values for vitamin A, zinc and phytate were taken from United States Department of Agriculture (USDA) food composition table [27] as well as the previous works of Yewelsew et al. [24] and Melaku et al. [28] on phytate and zinc content, adjusted for differences in moisture content. Due to limited resources, $50 \%$ of the sample size $(n=77)$ were taken by simple random sampling to investigate energy and nutrient intake of selected pregnant women in comparison with recommended dietary intake. 


\subsection{Statistical Analysis}

The total values of energy and nutrient consumption of the subjects were obtained by using the food processor software and then SPSS version 20 was employed to compute median intake. To compute the value, energy and nutrient content per $100 \mathrm{~g}$ was taken from Ethiopian food composition table, USDA and other literatures [26-28]. One-day weighed food record of the individual pregnant woman was measured in gram and entered separately in food processor in each food type weighed. Then the food processor software analyzed the energy and nutrient content of the food which the individual pregnant women consumed. Finally, the total amount of energy and nutrient intake of each of the selected individuals was taken to SPSS, and the median value was obtained and compared with recommended energy and nutrient intake. All other statistical analyses were carried out using SPSS version 20. The logistic regression was carried out to identify factors associated with nutritional status of the pregnant women. Then, the variables were checked for statistical significance. Multivariable logistic regression analysis was performed to examine the net effect of each independent variable on nutritional status of pregnant women, while controlling for the other independent variables.

Prior to starting the data collection, the Ethical Review Committee of the Hawassa University approved the study. The study design was also explained to officials of health office and administrative officers of Wondo Genet District for their permission and support. The nature of the study was fully explained to all pregnant women subjects included in the study to obtain verbal consent. Information was collected after getting consent from study participants. Data obtained from each study participant was kept confidential and all who participated in the study was acknowledged.

\section{Results}

The median age was 25 years for the study participants. The median family size was five persons, while more than half (54.9\%) of the households had more than five family members. More than half (52\%) of the study participants were with no formal education, while only $39.1 \%$ husbands did not receive any formal education. Majority of the study participants $(90.2 \%)$ were housewives, with about three-fourths (74.5\%) husbands were farmers. All of the study participants have been married on average for $8.5( \pm 5.6)$ years and $43.1 \%$ were in the age range of 25-29 years. Access to safe water (protected spring or public/private tape water) was reported by $90.8 \%$ of the respondents. Almost all of them (98.7\%) lived in male-headed households (Table 1).

The prevalence of visible goiter among the study subjects was $9.2 \%$. Out of the total subjects, $37.3 \%$ were pregnant for the first time and second time, $26.8 \%$ were for third and fourth time, and $10.5 \%$ were for more than seven times. More than one-third (39.9\%) of age of the last child of the respondents lie between 24 and 35 months, whereas $20.9 \%$ were below 24 months. More than half $(56.9 \%)$ of the study participants were following antenatal care during the study period. About $40 \%$ of the respondents reported that they had an experience of using family planning methods. The mean height of the study participants was $158.2 \pm 5.8 \mathrm{~cm}$ and majority (98\%) of the respondents had a height greater than or equal to 145 $\mathrm{cm}$. The median MUAC of the study participants was $24 \mathrm{~cm}$, and majority $(90.8 \%)$ was in a normal range $(\geq$ $21 \mathrm{~cm}$ ); however, 9.2\% was undernourished (MUAC 21) (Table 2).

Except iron $(58 \mathrm{mg})$ and riboflavin $(1.7 \mathrm{mg})$, other median nutrients and energy intakes of 2 nd trimester pregnant mothers were less than their requirement. Their energy intake was $2,308 \mathrm{kcal}$ which is low when compared to the recommended 2,340 kcal. Similarly, the iron intake $(42.5 \mathrm{mg})$ was higher in $3 \mathrm{rd}$ trimester pregnant mothers, while all the rest of the nutrients and energy intake were lower than the recommended intake. The energy intake of the study participants in 

Wondo Genet District, Southern Ethiopia

Table 1 Socio-Demographic characteristics of the study participants $(n=153)$.

\begin{tabular}{lll}
\hline Family characteristics & Frequency & Percent (\%) \\
\hline Age group (in years) & 8 & 5.2 \\
\hline $15-19$ & 50 & 32.7 \\
$20-24$ & 66 & 43.1 \\
$25-29$ & 24 & 15.7 \\
$30-34$ & 5 & 3.3 \\
$35-49$ & 25 years & \\
Median age in years & & \\
\hline Maternal education & 81 & 53.0 \\
\hline No formal education & 72 & 47.0 \\
Formal education & & \\
\hline Occupation of mother & 138 & 70.2 \\
\hline House wife & 11 & 7.2 \\
Petty trade & 4 & 2.6 \\
Daily laborer & & 45.1 \\
\hline Family size & 69 & 41.2 \\
\hline 2-4 family member & 63 & 13.7 \\
$5-7$ family member & 21 & \\
$>7$ family member & five person & 74.5 \\
Median & & 13.1 \\
\hline Husband's occupation & 114 & 10.5 \\
\hline Farmer & 20 & 2.0 \\
Daily laborer & 16 & \\
Merchant & 3 & \\
Employee & & \\
\hline
\end{tabular}

Table 2 Maternal health and anthropometry of the study participants $(n=153)$.

\begin{tabular}{lll}
\hline Maternal characteristics & Frequency & Percent (\%) \\
\hline Prevalence of observable goiter & 14 & 9.2 \\
\hline Pregnancy time & 57 & 37.3 \\
\hline $1-2$ & 41 & 26.8 \\
$3-4$ & 39 & 25.5 \\
$5-6$ & 16 & 10.5 \\
$\geq 7$ & & \\
\hline Age of last child & 35 & 22.9 \\
\hline st pregnancy & 32 & 20.9 \\
Less than 24 months & 7 & 4.6 \\
$24-35$ months & 61 & 39.9 \\
$36-47$ months & 18 & 11.8 \\
48 months and above & 87 & 56.9 \\
Antenatal care & 61 & 39.9 \\
Family planning & & 22.9 \\
\hline Parity (gravida) & 35 & 54.2 \\
\hline No parity & 83 & 22.9 \\
Less than four & 35 & \\
Four and more & & 2.0 \\
\hline Height in cm & 3 & 98.0 \\
\hline Height $<145.0 \mathrm{~cm}$ & 150 & \\
Height $\geq 145.0 \mathrm{~cm}$ & $158.2 \pm 5.8$ & 90.8 \\
Mean $( \pm$ SD) & 14 & \\
\hline MUAC in cm & 139 & \\
\hline MUAC $<21 \mathrm{~cm}$ & & \\
MUAC $\geq 21 \mathrm{~cm}$ & 14 & \\
\hline
\end{tabular}


Table 3 Energy and nutrient intakes of the 2nd trimester pregnancy mothers in comparison with estimated requirements and recommended intakes* $(n=35)$.

\begin{tabular}{lll}
\hline Item & Median (1st, 3rd quartiles) intake per day & Recommended dietary intake \\
\hline Energy $^{1}(\mathrm{kcal})$ & $2,308.3(1,374.8-3,084.8)$ & 2,340 \\
Protein $(\mathrm{g})$ & $45.9(33.2-83.1)$ & 71 \\
Calcium $^{2}(\mathrm{mg})$ & $811.4(443.6-1,189.2)$ & 1,000 \\
Iron $^{3}(\mathrm{mg})$ & $58.0(40.2-73.2)$ & 27 \\
Zinc $^{2}(\mathrm{mg})$ & $10.6(6.9-14.8)$ & 14 \\
Thiamin (mg) & $1.2(0.9-1.6)$ & 1.4 \\
Riboflavin (mg) & $1.7(1.1-2.5)$ & 1.4 \\
Niacin (mg) & $7.2(4.9-12.2)$ & 18 \\
Vitamin C (mg) & $13.5(7.7-25.7)$ & 55 \\
Vitamin A (retinol equivalent, $\mu \mathrm{g})$ & $3.0(0.4-20.2)$ & 800 \\
Phytate (mg) & $1,753.0(938.0-2,658.8)$ & \\
*Recommended nutrient intakes came from Ref. [29]. 1: energy requirement was estimated by assuming moderate physical activity; \\
2: calcium and zinc was assumed low bioavailability; 3: iron was assumed 5\% bioavailability.
\end{tabular}

Table 4 Energy and nutrient intakes of the 3rd trimester pregnancy mothers in comparison with estimated requirements and recommended intakes* $(n=42)$.

\begin{tabular}{lll}
\hline Item & Median (1st, 3rd quartiles) intake per day & Recommended dietary intake \\
\hline Energy $^{1}(\mathrm{kcal})$ & $1,420.5(1,051.7-2,274.5)$ & 2,452 \\
Protein $^{(\mathrm{g})}$ & $31.5(23.2-54.7)$ & 71 \\
Calcium $^{2}(\mathrm{mg})$ & $474.8(304.0-754.9)$ & 1,000 \\
$\mathrm{Iron}^{3}(\mathrm{mg})$ & $42.5(27.3-71.9)$ & 27 \\
Zinc $^{2}(\mathrm{mg})$ & $6.1(4.8-11.4)$ & 20 \\
Thiamin (mg) & $0.8(0.5-1.5)$ & 1.4 \\
Riboflavin (mg) & $1.3(0.7-2.0)$ & 1.4 \\
Niacin (mg) & $5.2(3.1-7.8)$ & 18 \\
Vitamin C (mg) & $10.1(5.2-18.9)$ & 55 \\
Vitamin A (retinol equivalent, $\mu \mathrm{g})$ & $3.1(0.3-8.4)$ & 800 \\
Phytate (mg) & $1,240.0(656.4-1,955.0)$ & \\
\hline
\end{tabular}

*Recommended nutrient intake came from Ref. [30]. 1: energy requirement was estimated by assuming moderate physical activity; 2 : calcium and zinc was assumed low bioavailability; 3 : iron was assumed 5\% bioavailability.

Table 5 Variables associated with maternal nutritional status (MUAC) of the study participants $(n=153)$.

\begin{tabular}{lllll}
\hline \multirow{2}{*}{ Variables } & \multicolumn{4}{c}{ Nutritional status } \\
\cline { 2 - 5 } & $\begin{array}{l}\text { Malnourished (MUAC }<21 \\
\mathrm{~cm}) \text { No. }(\%)\end{array}$ & $\begin{array}{l}\text { Normal (MUAC } \geq 21 \\
\mathrm{~cm}) \text { No. }(\%)\end{array}$ & Crude odds ratio (CI) & Adjusted odds ratio (CI) \\
\hline Age of mothers & $14(9.2)$ & $139(90.8)$ & $0.84(0.71-0.99)^{*}$ & - \\
\hline Eating cereal based foods & & & & \\
\hline Yes & $7(4.6)$ & $110(71.9)$ & 1 & 1 \\
No & $7(4.6)$ & $29(19.0)$ & $3.79(1.23-11.68)^{*}$ & $3.69(1.11-12.3)^{*}$ \\
\hline Having beans or peas & & & & \\
\hline Yes & $7(4.6)$ & $107(69.9)$ & $3.34(1.091-10.244)^{*}$ & - \\
No & $7(4.6)$ & $32(20.9)$ & $1.48(0.95-2.31)$ & $1.96(1.02-3.75)^{*}$ \\
\hline Multiple pregnancy & $14(9.2)$ & $139(90.8)$ & &
\end{tabular}

$* P$ value $<0.05$. CI: confidence interval.

3rd trimester of pregnancy was $1,420.5 \mathrm{kcal}$, which is very much lower when compared to the recommended 2,452 kcal. Vitamin A intake was considerably lower than the recommended intake, i.e., only about $3 \mu \mathrm{g}$ for both 2nd and 3rd trimester pregnant mothers (Tables 3 and 4). Risk factors identified for undernutrition were 
only multiple pregnancy and no consumption of cereal-based foods. Multiple pregnancy and no consumption of cereal-based foods have a significant association on the nutritional status (mid upper arm cercumference) of the pregnant women with adjusted odds ratio $(\mathrm{AOR})=1.96,95 \%$ confidence interval $(\mathrm{CI})$ $=(1.02-3.75)$ and $\mathrm{AOR}=3.69,95 \% \mathrm{CI}=(1.11-12.29)$, respectively (Table 5).

\section{Discussion}

The study showed that $9.2 \%$ of the respondents were undernourished and almost all nutrient intakes of pregnant women were below the recommended level. This finding is consistent with one study conducted in Africa which showed that many women in Africa suffered from chronic energy deficiency, inadequate weight gain and poor nutritional status [18]. The reasons for the observed undernutrition in the current study participants might be due to their poor educational status, smaller land holding, larger family size and the recurrent food insecurity. It was found that the mean energy intake of both the 2nd and 3rd trimester pregnant women was below the recommendation. It was indicated that approximately 60,000 kilocalories are required to meet the energy demands of both maternal and fetal tissues during the course of pregnancy [15]. It was also observed that energy intake of pregnant women during the 2 nd and 3rd trimester was lower than the recommended level, which is contrary to what is expected. This might be due to their full activity during the whole course of pregnancy and no increased food intake in amount and frequency. Yewelsew et al. [24] also reported that estimated energy intakes of the subsistence pregnant women were very low, and all the women had adjusted energy intakes below the FAO mean energy requirement estimate. According to King [31], the total amount of protein needed for the fetus, placenta, amniotic fluid, uterus, blood and extra cellular fluid is estimated at $925 \mathrm{~g}$ for a normal 270-day pregnancy, with $760 \mathrm{~g}$ accumulated in the last 20 weeks of pregnancy. Even though protein is very important for growth of tissue of both the mother and the fetus, the current study showed that the total protein intake of pregnant women in both groups was much lower than the recommended intakes. Similar finding was reported in Malawi, where pregnant women were predicted to be at risk of inadequate intakes of dietary protein [29]. The low intake of dietary protein revealed in the current study might be as a result of low intake of animal source foods by study subjects (consumption of organ meat $7.2 \%$; flesh meat $12.4 \%$; egg $11.1 \%$; fish $2.6 \%$ ). In general, the dietary intake of pregnant and lactating women in Africa showed inadequacies of several micronutrients, particularly iron, vitamin A, zinc, folic acid, riboflavin, iodine, calcium and vitamin E [18]. The current study also revealed that almost all micronutrients intakes of the pregnant women were below the recommendation for such nutrients. Only the iron intake of the current study participants was above the recommendation in both trimesters. This finding is comparable with the previous work of Yewelsew et al. [24], which showed very few of the pregnant women in Sidama Zone were at risk of inadequate intakes of iron. This may be due to the high content of iron in Ethiopian diets as has been emphasized by Gebre-Medhin [30]. He indicated that the consumption of the indigenous cereal teff ( $E$. teff), oleaginous seeds, Ethiopian kale (B. carinata braun) and all foods that appear to contain relatively high levels of iron enhances iron intake [30]. In the current study, it was found that the pregnant women's dietary intake of vitamin A was very much lower than the recommended intakes. This might be because of the much lower intake of animal source foods that contain preformed vitamin A (retinol). Women of reproductive age are thought to be vulnerable to VAD during pregnancy and lactation because, they often report night blindness [32, 33]. The results in this study showed that dietary zinc intake of pregnant women was lower than the recommended intakes. The requirement of zinc increases with the increased 
gestational age. This is related with the importance of zinc as a component of a large number of enzymes participating in the synthesis and degradation of carbohydrates, lipids, proteins, nucleic acids and in the metabolism of other micronutrients whose requirement increases in general with progressing pregnancy [34], but the dietary zinc intake decreased in 3rd trimester pregnant women. A study among low income American women with plasma zinc concentrations below the mean at enrolment in prenatal care showed that a zinc intake of $25 \mathrm{mg} / \mathrm{d}$ resulted in greater infant birth weights, head circumferences as well as a reduced frequency of low birth weight infants among non-obese women compared with the placebo group [35]. Yewelsew et al. [24] also reported similar finding on the pregnant women in the study conducted in Sidama Zone, Southern Ethiopia. As it was observed with the other micronutrients, calcium intake was also lower than the recommendation in both of the study groups. Its intake was much lower (below half of the requirement) in case of the 3 rd trimester pregnant mothers. Similar finding was reported in previous study conducted by Yewelsew et al. [24], which showed that inadequate calcium intake was obtained in the study carried out among the pregnant women population in Sidama Zone, Southern Ethiopia. Pregnant women are one of populations at risk of calcium deficiency especially in the last trimester [35]. It was observed that all the other micronutrients, such as riboflavin (not for second trimester), thiamin, niacin and vitamin $\mathrm{C}$ intakes were lower than the recommended intakes. As the number of pregnancy increased, the likelihood of a woman being malnourished (MUAC $<21 \mathrm{~cm}$ ) is 1.96 times more. This may be due to closely spaced pregnancies which are often associated with the mother having little time to regain lost fat and nutrient stores. Similarly, a pregnant woman who did not consume cereal based foods in $24 \mathrm{~h}$ recall of their food in previous day of the survey was 3.7 times more likely to be malnourished when compared to their counter parts who consumed cereals. This may be due to increased number of pregnancy and more dependency on cereal foods which are important factors resulting in undernutrition.

\section{Conclusions}

The study showed that energy and nutrient intakes of the study subjects was not in line with normal range and recommendation to maintain the nutritional requirement of the pregnant women. The energy and nutrient intakes of the 3rd trimester pregnant women were lower than that of the 2nd trimester pregnant women. As a whole, in both cases, the respondents' intake of energy and nutrient intake was lower than the recommended intake. This can be aggravated by high phytate content food, such as cereal and legume foods consumed. In general, the nutritional status of pregnant women in Wondo Genet district were not adequate and not in line with the national and international guidelines to support their increased energy and nutrient requirement.

\section{Acknowledgments}

The authors want to thank NORAD project coordination office and Kindo Didaye District Administration office for financing the research fund. Our gratitude also goes to those who involved directly or indirectly in the accomplishment of this research.

\section{References}

[1] West, J., and Keith, P. 2002. "Extent of Vitamin A Deficiency among Preschool Children and Women of Reproductive Age.” J. Nutr. 132 (9): 2857S-66S.

[2] Mason, J. B., Lotfi, M., Dalmiya, N., Sethuraman, K., Deitchler, M., Geibel, S., Gillenwater, K., Gilman, A., Mason, K., and Mock, N. 2001. "The Micronutrient Report: Current Progress in the Control of Vitamin A, Iodine and Iron Deficiencies." Micronutrient Initiative/International Development Research Center, Ottowa, Canada. Accessed November 2014. http://www.micronutrient.org/frame_HTML/resource_tex t/publications/mn_report.pdf.

[3] Kennedy, G., Nantel, G., and Shetty, P. 2001. "The Scourge of 'Hidden Hunger': Global Dimensions of 
Micronutrient Deficiencies." Food and Agriculture Organization. Accessed November 2014. http://www.fao.org/docrep/005/y8346m/y8346m02.htm.

[4] Muller, O., and Krawinkel, M. 2005. "Malnutrition and Health in Developing Countries." Canadian Medical Association Journal 173 (3): 279-86.

[5] Girma, W., and Timotiows, G. 2002. Determinants of Nutritional Status of Women and Children in Ethiopia. Calverton, Maryland, USA: ORC Macro, 2-13.

[6] Pena, M., and Bacalao, J. 2002. "Malnutrition and Poverty." Ann. Rev. Nutr. 22: 241-53.

[7] Okwu, G. N., Ukoha, A. I., Nwachukwu, N., and Agha, N. C. 2007. "Studies on the Predisposing Factors of Protein Energy Malnutrition among Pregnant Women in a Nigerian Community." Online J. Health Allied Sci. 6 (3): 1. Accessed September 2014. http://www.oalib.com/paper/2656617.

[8] Shetty, P. S., and James, W. P. T. 1994. "Body Mass Index: A Measure of Chronic Energy Deficiency in Adults." FAO Food and Nutrition Paper 56, Rome. Accessed August 2014. http://www.fao.org/docrep/t1970e/t1970e00.htm.

[9] Hutter, I. 1996. "Reduction of Food Intake during Pregnancy in Rural South India." Tropical Medicine and International Health 1 (3): 399-405.

[10] Siega-Riz, A. M., Hermann, T. S., Savitz, D. A., and Thorp, J. M. 2001. "Frequency of Eating during Pregnancy and Its Effect on Preterm Delivery." American Journal of Epidemiology 153 (7): 647-52.

[11] Martorell, R., Ramakrishnan, U., and Schroeder, D. G. 1998. "Intrauterine Growth Retardation, Body Size, Body Composition and Physical Performance in Adolescence." European Journal of Clinical Nutrition 52 (1): 43S-52S.

[12] Karim, R., Bhat, D., Troy, L., Lamstein, S., and James-Levinson, F. 2002. "Determinants of Food Consumption during Pregnancy in Rural Bangladesh: Examination of Evaluative Data from the Bangladesh Integrated Nutrition Project.” Discussion Paper No. 11, IDEAS. Accessed April 2014. https://ideas.repec.org/p/ fsn/wpaper/11.html.

[13] Ministry of Planning Economic Development (MOPED). 1999. "Poverty Situation in Ethiopia." Welfare Monitoring Unit, Addis Ababa, Ethiopia. Accessed July 2013. www.mofed.gov.et/m/Resources/MEDR\%20EFY1 999-Annual-2.pdf.

[14] Ethiopia Central Statistical Agency and ORC Macro. 2005. Ethiopia Demographic and Health Survey. Central Statistical Agency and ORC Macro, Addis Ababa, Ethiopia and Calverton, Maryland, USA.

[15] Pannel on Macronutrients, Institute of Medicine. 2002. Report on Dietary Reference Intakes for Energy, Carbohydrate, Fiber, Fat, Fatty Acids, Cholesterol,
Protein and Amino Acids.

[16] Brown, L. S. 2011. "Nutrition Requirement during Pregnancy." Accessed June 2015. samples.jbpub.com/ 9780763777920/77920_CH01_001_024.pdf.

[17] Kathryn, G. D. 2003. "Facilitating Improved Nutrition for Pregnant and Lactating Women and Children 0-5 Years of Age Commenting: Black, Reifsnider and Devaney." Encyclopedia on Early Childhood Development. Accessed April 2014. http://www.child-encyclopedia. com/nutrition-pregnancy/according-experts/facilitating-i mproved-nutrition-pregnant-and-lactating-women.

[18] Huffman, S. L., Zehner, E. R., Harvey, P., and Martin, L. 2001. "Essential Health Sector Actions to Improve Maternal Nutrition in Africa." Regional Centre for Quality of Care and Linkages Project, Academy for Educational Development, Washington, DC. Accessed November 2014. www.who.int/entity/pmnch/media/.../ opportunidades_port_end.pdf.

[19] Loaiza, E. 1997. "Maternal Nutritional Status." Demographic and Health Surveys Comparative Studies No. 24, Macro International Inc., Calverton, Maryland, USA. Accessed November 2014. pdf.usaid.gov/ pdf_docs/PNACC716.pdf.

[20] Teller, H., and Yimar, G. 2000. "Levels and Determinants of Malnutrition in Adolescent and Adult Women in Southern Ethiopia." Ethiopian Journal of Health Development 14 (1): 57-66.

[21] Zerihun, T., Larson, C. P., and Hanley, J. A. 1997. "Anthropometric Status of Oromo Women of Child Bearing Age in Rural Southwestern Ethiopia." Ethiopian Journal of Health Development 11 (3): 1-7.

[22] Ferro-Luzzi, A., Scaccini, C., Taffese, S., Aberra, B., and Demeke, T. 1990. "Seasonal Energy Deficiency in Ethiopian Rural Women.” European Journal of Clinical Nutrition 44 (1): 7S-18S.

[23] Ethiopia Central Statistical Agency and ICF International. 2011. Ethiopia Demographic and Health Survey. Central Statistical Agency and ICF International, Addis Ababa, Ethiopia and Calverton, Maryland, USA.

[24] Yewelsew, A. K., Hambidge, B., Stocker, N., Krebs, K., and Bailey-Gibson, R. S. 2007. "Is Phytate Likely to Compromise Iron, Zinc and Calcium Bioavailability in Rural Southern Ethiopian Diets Based on Cereals and Enset Starchy Foods?" Journal of Food Consumption and Analysis 120: 161-8.

[25] Gibson, R. S., and Ferguson, E. L. 1999. An Interactive 24 Hour Recall Method for Assessing Intakes of Iron in Developing Countries. Washington, DC: ILSI Press, 31-43.

[26] Ethiopian Health and Nutrition Research Institute (EHNRI). 1998. Food Composition Table for Use in Ethiopia. Addis Ababa: EHNRI, 34. 
[27] United States Department of Agriculture (USDA). 2003. "National Nutrient Database for Standard Reference." Nutrient Data Laboratory, U.S. Government Printing Office, Washington, DC. Accessed March 2015. $\mathrm{http} / / / \mathrm{www}$. nal.usda.gov/fnic/foodcomp.

[28] Melaku, U., West, C. E., and Fufa, H. 2005. "Content of Zinc, Calcium and Their Absorption Inhibitors in Foods Commonly Consumed in Ethiopia." Journal of Food Composition and Analysis 18 (8): 803-17.

[29] Gibson, R. S., and Huddle, J. M. 1998. "Suboptimal Zinc Status in Pregnant Malawian Women: Its Association with Low Intakes of Poorly Available Zinc, Frequent Reproductive Cycling and Malaria." American Journal of Clinical Nutrition 67 (4): 702-9.

[30] Gebre-Medhin, M., Killander, A., Vahlquist, B., and Wuhib, E. 1976. "Rarity of Anemia in Pregnancy in Ethiopia." Scandinavian Journal of Haematology 16 (3): 168-75.

[31] King, J. C. 2000. "Physiology of Pregnancy and Nutrient
Metabolism.” Am. J. Clin. Nutr. 71 (5): 1218S-25S.

[32] Bloem, M. W., Matzger, H., and Huq, N. 1995. "Vitamin A Deficiency among Women in the Reproductive Years: An Ignored Problem." In Proccedings of the XVI International Vitamin A Consultative Group Meeting, 78.

[33] Christian, P., West, K. P. Jr., Khatry, S. K., Katz, J., Shrestha, S. R., Pradhan, E. K., LeClerq, S. C., and Pokhrel, R. P. 1998. "Night Blindness of Pregnancy in Rural Nepal-Nutritional and Health Risks." International Journal of Epidemiology 27 (2): 231-7.

[34] Joint FAO/WHO. 1998. Vitamin and Mineral Requirements in Human Nutrition. Report of a Joint FAO/WHO Expert Consultation, Bangkok, Thailand.

[35] Goldenberg, R. L., Tamura, T., Neggers, Y., Copper, R. L., Johnston, K. E., DuBard, M. B., and Hauth, J. C. 1995. "The Effect of Zinc Supplementation on Pregnancy Outcome." Journal of the American Medical Association 274 (6): 463-8. 